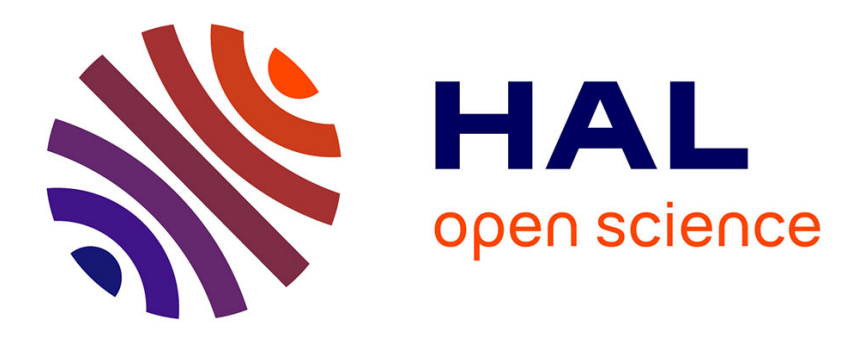

\title{
What Makes the Trifluoride Anion F3- So Special? A Breathing-Orbital Valence Bond ab Initio Study
}

\author{
Benoît Braïda, Philippe C. Hiberty
}

\section{To cite this version:}

Benoît Braïda, Philippe C. Hiberty. What Makes the Trifluoride Anion F3- So Special? A BreathingOrbital Valence Bond ab Initio Study. Journal of the American Chemical Society, 2004, 126 (45), pp.14890-14898. 10.1021/ja046443a . hal-01627886

\section{HAL Id: hal-01627886 \\ https://hal.science/hal-01627886}

Submitted on 9 Nov 2017

HAL is a multi-disciplinary open access archive for the deposit and dissemination of scientific research documents, whether they are published or not. The documents may come from teaching and research institutions in France or abroad, or from public or private research centers.
L'archive ouverte pluridisciplinaire HAL, est destinée au dépôt et à la diffusion de documents scientifiques de niveau recherche, publiés ou non, émanant des établissements d'enseignement et de recherche français ou étrangers, des laboratoires publics ou privés. 


\title{
What Makes the Trifluoride Anion $\mathbf{F}_{3}{ }^{-}$So Special? A Breathing-Orbital Valence Bond ab Initio Study
}

\author{
Benoit Braïda ${ }^{\dagger}$ and Philippe C. Hiberty*,‡ \\ Contribution from the Laboratoire de Chimie Théorique (UMR-CNRS 7616), \\ Université Pierre et Marie Curie, 4 place Jussieu, 75252 Paris Cédex, France, and \\ Laboratoire de Chimie Physique, Groupe de Chimie Théorique, Bat. 490, \\ Université de Paris-Sud, 91405 Orsay Cédex, France \\ E-mail: philippe.hiberty@ıcp.u-psud.fr
}

\begin{abstract}
The ground states of the $\mathrm{F}_{3}{ }^{-}$and $\mathrm{H}_{3}{ }^{-}$hypercoordinated anions are investigated and analyzed in terms of valence bond structures by means of the breathing-orbital valence bond method. While $\mathrm{H}_{3}{ }^{-}$is described reasonably well as the interplay of two major Lewis structures, $\mathrm{H}_{2}+\mathrm{H}^{-}$and its mirror image, the description of $\mathrm{F}_{3}{ }^{-}$requires a further structure, of the type $\mathrm{F}^{\cdot} \mathrm{F}^{-} \mathrm{F} \cdot$; which strongly stabilizes the trimer relative to the dissociation products, and endows the $\mathrm{F}_{3}{ }^{-}$ground state with a predominant three-electron bond character. It follows that the simple picture that is closest to the true nature of $\mathrm{F}_{3}{ }^{-}$is a resonating combination of $\mathrm{F}_{2}{ }^{-}+\mathrm{F}^{\bullet}$ and its mirror image. This peculiarity of the $\mathrm{F}_{3}{ }^{-}$electronic structure is at the origin of its preferred dissociation channel leading to $\mathrm{F}_{2}^{-}+\mathrm{F}^{-}$rather than to the most stable product $\mathrm{F}_{2}+\mathrm{F}^{-}$, at high collision energies. The three-electron bond character of $\mathrm{F}_{3}{ }^{-}$is also the root cause for the failure of the HartreeFock and density functional methods for this species, and for its strong tendency to artifactual symmetrybreaking. As an alternative to the Rundle-Pimentel model, the origins of the stability of $\mathrm{F}_{3}{ }^{-}$, as opposed to the instability of $\mathrm{H}_{3}{ }^{-}, \mathrm{CH}_{5}{ }^{-}$, and other $\mathrm{S}_{\mathrm{N}} 2$ transition states, are analyzed in the framework of valence bond state correlation diagrams [Shaik, S.; Shurki, A. Angew. Chem., Int. Ed. 1999, 38, 586]. It is found that a fundamental factor of stability for $\mathrm{X}_{3}{ }^{-}$is the presence of lone pairs on the $\mathrm{X}$ fragment. The explanation carries over to other trihalide anions, and to isoelectronic 22-valence electron hypercoordinated anions.
\end{abstract}

\section{Introduction}

Hypervalent compounds, defined as molecules or ions that violate the octet rule, are always challenging cases for simple models of chemical bonding, especially when they are strongly bound. In this context, halogens atoms are known to form hypervalent anions of the type $\mathrm{X}_{3}{ }^{-}$, which are stable against dissociation to $\mathrm{X}_{2}+\mathrm{X}^{-}$. Evidence for the existence of trifluoride anion, $\mathrm{F}_{3}{ }^{-}$, has first been reported in $1976 .{ }^{1}$ This anion has been observed in rare gas matrix ${ }^{1,2}$ and in the gas phase. ${ }^{3,4}$ Other trihalides anions, $\mathrm{Cl}_{3}{ }^{-}, \mathrm{Br}_{3}{ }^{-}$, and $\mathrm{I}_{3}{ }^{-}$, have also been observed in the gas phase, ${ }^{5}$ in solution, ${ }^{6,7}$ and in the solid state. ${ }^{6,8}$ The experimental structures of these anions have been determined by spectroscopic methods. ${ }^{1,2 a, 9-11}$ They are linear and symmetric

† Université Pierre et Marie Curie. E-mail: braida@1ct.jussieu.fr.

$\doteqdot$ Université de Paris-Sud. Associated with the CNRS, UMR 8000 .

(1) Ault, B. S.; Andrews, L. J. Am. Chem. Soc. 1976, 98, 1591.

(2) (a) Ault, B. S.; Andrews, L. Inorg. Chem. 1977, 16, 2024. (b) Hunt, R. D.; Thompson, C.; Hassanzadeh, P. Andrews, L. Inorg. Chem. 1994, 33, 388

(3) Tuinman, A. A.; Gakh, A. A.; Hinde, R. J.; Compton, R. N. J. Am. Chem. Soc. 1999, 121, 8397.

(4) Artau, A.; Nizzi, K. E.; Hill, B. T.; Sunderlin, L. S.; Wenthold, P. G. J. Am. Chem. Soc. 2000, 122,10667

(5) Nizzi, K. E.; Pommerening, C. A.; Sunderlin, L. S. J. Phys. Chem. A 1998 $102,7674$.

(6) Downs, A. J.; Adams, C. J. In Comprehensive Organic Chemistry; Bailar, J. C., Jr., Ed.; Pergamon Press: Oxford, U.K., 1973; Vol. 2, p 1534, and references therein.

(7) Nelson, I. V.; Iwamoto, R. T. J. Electroanal. Chem. 1964, 7, 218

(8) (a) Robertson, K. N.; Bakshi, P. K.; Cameron, T. S.; Knop, O. Z. Anorg. Allg. Chem. 1997, 623, 104. (b) Robertson, K. N.; Cameron, T. S.; Knop, O. Can. J. Chem. 1996, 74, 1572. (c) Bogaard, M. P.; Peterson, J.; Rae, A. D. Acta Crystallogr., Sect. B 1981, 37, 1357. in the gas phase and in solution, while in the solid state both symmetric and asymmetric structures are found, ${ }^{8 c, 12}$ as well as small deviations from linearity, because of crystal packing forces. The gas-phase $0 \mathrm{~K}$ bond strengths $D\left(\mathrm{X}_{2}-\mathrm{X}^{-}\right)$of the polyhalide anions have been measured using energy-resolved collision-induced dissociation and amount to ca. 22-25 $\mathrm{kcal} / \mathrm{mol}$ for $\mathrm{Cl}_{3}{ }^{-}, 529-32 \mathrm{kcal} / \mathrm{mol}$ for $\mathrm{Br}_{3}{ }^{-}, 529-32 \mathrm{kcal} / \mathrm{mol}$ for $\mathrm{I}_{3}{ }^{-4,13}$ and $21-26 \mathrm{kcal} / \mathrm{mol}$ for $\mathrm{F}_{3}{ }^{-4}$ One remark rarely made about these bonding energies is how amazingly large they are. For $\mathrm{F}_{3}{ }^{-}$, the average $0 \mathrm{~K}$ bond strength of each formal hemibond is $30 \mathrm{kcal} / \mathrm{mol}$ for a formal bond order of 0.5 , not far from the $38 \mathrm{kcal} / \mathrm{mol}$ bond strength of a genuine $\mathrm{F}_{2}$ bond. ${ }^{14}$ More generally, one may wonder which driving force or physical interaction may cause a nonpolar, saturated, and already

(9) (a) Ault, B. S.; Andrews, L. J. Chem. Phys. 1976, 64, 4853. (b) Ault, B. S.; Andrews, L. J. Am. Chem. Soc. 1975, 97, 3824. (c) Evans, J. C.; Lo, G. Y.-S. J. Chem. Phys. 1966, 44, 3638.

(10) (a) Person, W. B ; Anderson, G. R. Fordemwalt, J. N * Stammreich, H Forneris, R. J. Chem. Phys. 1961, 35, 908. (b) Kiefer, W.; Bernstein, H. J. Chem. Phys. Lett. 1972, 15, 5. (c) Parret, F. W.; Tailor, N. J. J. Inorg. Nucl. Chem. 1970, 32, 2458. (d) Gabes, W.; Gerding, H. J. Mol. Struct. 1972, 14, 267.

(11) (a) Mohmmad, M. R.; Sherman, W. F. J. Mol. Struct. 1984, 115, 27. (b) Loos, K. R.; Jones, A. C. J. Chem. Phys. 1974, 78, 2306

(12) (a) Cotton, F. A.; Lewis, G. E.; Schwetzer, W. Inorg. Chem. 1986, 25, 3528 and references therein. (b) Rosshirt, E. F.; Frey, F.; Boysen, H.; Jagodzinski, H. Acta Crystallogr., Sect. B 1985, 41, 66.

(13) Do, K.; Klein, T. P.; Pommerening, C. A.; Sunderlin, L. S. J. Am. Soc. Mass Spectrom. 1997, 8, 688.

(14) Chase, M. W., Jr.; Davies, C. A.; Downey, J. R.; Frurip, D. J.; McDonald, R. A.; Syverud, A. N. J. Phys. Chem. Ref. Data 1985, 14, Suppl. 1. 
Scheme 1

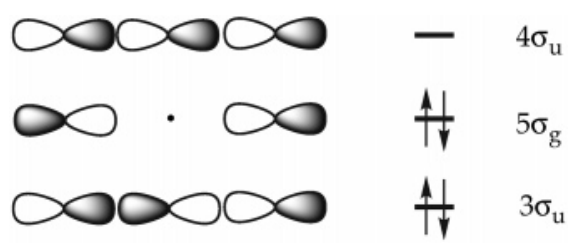

electron-rich molecule $\mathrm{X}_{2}$ to attract a closed shell anion like $\mathrm{X}^{-}$and form with it a stable aggregate. While the stability of other electron-rich aggregates such as $\mathrm{FHF}^{-}$or $\mathrm{BrHBr}^{-}$can be understood in terms of a predominant low-lying ionic structure $\mathrm{X}^{-} \mathrm{H}^{+} \mathrm{X}^{-}$, no such ionic structure has a chance to play a major role in $\mathrm{X}_{3}^{-}$, and the Lewis representation $\mathrm{F}^{-} \mathrm{F}^{+} \mathrm{F}^{-}$that has been proposed for $\mathrm{F}_{3}{ }^{-}$is hardly convincing, in view of the large ionization potential of fluorine.

Hypervalency in electron-rich systems is usually explained in terms of the Rundle-Pimentel model..$^{15,16}$ This model, based on simple molecular orbital (MO) theory, discards the early Pauling's proposal of a participation of $d$ orbitals in terms of an $\mathrm{sp}^{3} \mathrm{~d}$ hybridization of the central atom. ${ }^{17}$ Restricting the reasoning to the three axial $\mathrm{p}$ orbitals that are involved in the $\sigma$ bonds, the three schematic MOs depicted in Scheme 1 are formed in the linear complex. As the two lowest occupied MOs are either strongly bonding or nonbonding in $\mathrm{X}_{3}{ }^{-}$, some stability is expected. This is of course a rough picture, which neglects many factors among which the mixing of the highest occupied MOs with the underlying 2 s orbitals, which adds some antibonding character to the $5 \sigma_{\mathrm{g}} \mathrm{MO} .{ }^{18}$ The amount of such mixing, as well as the repulsive interactions arising from the lower MOs and their consequence on the stability of $\mathrm{X}_{3}{ }^{-}$and isoelectronic clusters, have been studied in detail by Hoffmann. ${ }^{18}$ More disturbing for the Rundle-Pimentel model is its failure to account for the instability of simple related systems, such as $\mathrm{H}_{3}{ }^{-}$and $\mathrm{CH}_{5}{ }^{-} \cdot \mathrm{H}_{3}{ }^{-}$is a transition state in the $\mathrm{H}^{-}+\mathrm{H}_{2} \rightarrow \mathrm{H}_{2}$ $+\mathrm{H}^{-}$exchange reaction, lying $11 \mathrm{kcal} / \mathrm{mol}$ above the reactants, and $\mathrm{CH}_{5}{ }^{-}$, the transition state for the simplest model $\mathrm{S}_{\mathrm{N}} 2$ reaction, lies some $50 \mathrm{kcal} / \mathrm{mol}$ over $\left(\mathrm{H}^{-}+\mathrm{CH}_{4}\right) \cdot{ }^{19,20}$ To quote Kutzelnigg, ${ }^{21}$ "Whereas simple MO theory has no difficulty in describing three-center, two-electron bonds such as that in $\mathrm{H}_{3}{ }^{+}$, problems do arise in the description of three-center, four-electron bonds since for $\mathrm{H}_{3}{ }^{-}$it incorrectly predicts a strong bond with respect to $\mathrm{H}_{2}$ and $\mathrm{H}^{-}$. The failure of simple $\mathrm{MO}$ theory for $\mathrm{H}_{3}{ }^{-}$ is not easy to understand." One of the objectives of the present work is to see if VB theory is more successful in this respect.

A number of theoretical studies of trihalide anions ${ }^{18,22-28}$ have been published in recent years, the most numerous papers

(15) Hach, R. J.; Rundle, R. E. J. Am. Chem. Soc. 1951, 73, 4321.

(16) Pimentel, C. G. J. Chem. Phys. 1951, 19, 446.

(17) Pauling, L. The Nature of the Chemical Bond, 3rd ed.; Cornell University Press: Ithaca, NY, 1960; p 145.

(18) Munzarova, M. L.; Hoffmann, R. J. Am. Chem. Soc. 2002, 124, 4787.

(19) Maître, P.; Volatron, F.; Hiberty, P. C.; Shaik, S. S. Inorg. Chem. 1990, 29, 3047.

(20) One might object that $\mathrm{CH}_{5}{ }^{-}$collapses to $\mathrm{H}^{-}+\mathrm{CH}_{4}$ because the central $\mathrm{CH}_{3}$ gets pyramidal as the reaction coordinate goes from the transition state to the reactants or products, leading to a hybridization of the axial central orbital from pure $\mathrm{p}$ to $\mathrm{sp}^{3}$. However, some test calculations at the MP2/ 6-31+G(d) level show that $\mathrm{CH}_{5}{ }^{-}$remains unstable against dissociation even if the central $\mathrm{CH}_{3}$ fragment is held planar.

(21) Kutzelnigg, W. Angew. Chem., Int. Ed. Engl. 1984, 23, 272, footnote 106.

(22) Novoa, J. J.; Mota, F.; Alvarez, S. J. Phys. Chem. 1988, 92, 6561.

(23) Ogawa, Y.; Takahashi, O.; Kikuchi, O. J. Mol. Struct. (THEOCHEM) 1998, $424,285$.

(24) Danovitch, D.; Hrusak, J.; Shaik, S. Chem. Phys. Lett. 1995, 233, 249

(25) Cahill, P. A.; Clifford, E. D.; Martin, J. C. J. Am. Chem. Soc. 1985, 107, 6359. dealing with the trifluoride anion alone. ${ }^{25-28}$ Interest about this latter complex was stimulated by the amazingly difficult challenge that it poses to quantum chemistry, despite its relatively small size. This molecule has an exceptional multireference character, even larger than that of classical cases such as $\mathrm{F}_{2}$ or FOOF, 27 and is subject to strong symmetry-breaking. ${ }^{28}$ The most sophisticated calculation to date employs the orbital doubling procedure, a classical means of resolving symmetry-breaking instabilities, leading to an MCSCF + MP2 calculation with a complete active space of 7 orbitals and 8 electrons $(\operatorname{CAS}(7,8))$. This calculation yields a bonding energy of $28.2 \mathrm{kcal} / \mathrm{mol}$, while a lower active space (CAS $(6,4)+\mathrm{MP} 2)$ gives a somewhat larger value of $30.2 \mathrm{kcal} / \mathrm{mol} .{ }^{28}$ An estimation of the large basis set limit for a $\operatorname{CCSD}(\mathrm{T})$ calculation yields a theoretical window of $26 \pm 3.5 \mathrm{kcal} / \mathrm{mol}$ for the bonding energy. ${ }^{27}$ All of these values should be compared with the experimental value $24.0 \pm 2.5$ $\mathrm{kcal} / \mathrm{mol}$ obtained by adding ZPE corrections to the measured $0 \mathrm{~K}$ bond strength of $\mathrm{F}_{3}{ }^{-28}$ In view of the moderate convergence of present high-quality results, it is perhaps fair to say that the definitive calculation on $\mathrm{F}_{3}{ }^{-}$is still to come. Lower levels of calculations are inappropriate: different DFT functionals (VWN, LYP, B-P, BLYP, PW) consistently overestimate the $D_{\mathrm{e}}\left(\mathrm{F}_{2}-\mathrm{F}^{-}\right)$bonding energy, ${ }^{26}$ yielding values ranging from 45 to $78 \mathrm{kcal} / \mathrm{mol}$. The B3LYP functional gives a more reasonable value of $33.7 \mathrm{kcal} / \mathrm{mol}$, but finds the two dissociation products, $\left(\mathrm{F}_{2}+\mathrm{F}^{-}\right)$and $\left(\mathrm{F}_{2}^{-}+\mathrm{F}^{\circ}\right)$, in the wrong order. ${ }^{4}$ On the other hand, the Hartree-Fock method severely underestimates the $\left(\mathrm{X}_{2}-\mathrm{X}^{-}\right)$bond strengths for all halogens. ${ }^{23}$ Last, low orders of perturbation theory have been found to be unreliable for the trifluoride anion. ${ }^{27}$ As will be seen below, the poor performances of low theoretical levels as well as the tendency of $\mathrm{F}_{3}^{-}$to undergo symmetry-breaking artifacts can be simply interpreted in valence bond terms.

One last intriguing feature of the trifluoride anion lies in the observed branching ratio between the two competing collisioninduced dissociation pathways, reactions 1 and 2 .

$$
\begin{aligned}
& \mathrm{F}_{3}^{-} \rightarrow \mathrm{F}_{2}+\mathrm{F}^{-} \\
& \mathrm{F}_{3}^{-} \rightarrow \mathrm{F}_{2}^{-}+\mathrm{F}^{\bullet}
\end{aligned}
$$

Although reaction 1 is energetically favored by the electron affinity difference between $\mathrm{F}^{\bullet}$ and $\mathrm{F}_{2}$ (3.40 and $3.08 \mathrm{eV}$, respectively), ${ }^{29}$ at high collision energy with argon $(25 \mathrm{eV})$, reaction 2 predominates by a factor of $3 .{ }^{3}$ While a slight predominance of reaction 2 over reaction 1 has been explained in terms of density of states at low collision energies $(3 \mathrm{eV}),{ }^{4}$ we believe that the explanation does not hold for the much larger predominance that is observed at high energies, in which case diabatics effects are usually invoked: in such a case, the favored dissociation product is the one whose electronic structure most resembles that of the trimer's ground state. Yet, it is clear that a deep knowledge of the physical content of the $\mathrm{F}_{3}{ }^{-}$wave function is needed before such an explanation can be put forward.

(26) Sosa, C.; Lee, C.; Fitzgerald, G.; Eades, R. A. Chem. Phys. Lett. 1993 $211,265$.

(27) Heard, G. L.; Marsden, C. J.; Scuseria, G. E. J. Phys. Chem. 1992, 96, 4359.

(28) Mota, F.; Novoa, J. J. J. Chem. Phys. 1996, 105, 8777.

(29) Blondel, C.; Cacciani, P.; Delsart, C.; Trianham, K. Phys. Rev. A 1989, 40,3698 . 
The above intriguing features of the trifluoride anion require a qualitative understanding of its electronic structure, and this can be achieved only with the help of a compact wave function which, despite its compactness, incorporates the essential ingredients that are required for a realistic description of the ground state, and in particular electron correlation. Such requirements can be fulfilled in the framework of valence bond (VB) theory, which has often proved to bring additional insight relative to MO theory, by expressing wave functions from a more "chemical" point of view. We have therefore carried out the study of the two dissociation channels of $\mathrm{F}_{3}{ }^{-}$, reactions 1 and 2, by means of the "breathing-orbital valence bond" method (BOVB), a modern VB method that has been devised to combine the simplicity and interpretability of the classical VB description (only six VB structures here) with reasonable accuracy (the relation of the BOVB method with other formulations will be discussed below) ${ }^{30}$ In this line, our objective is to provide some answers to the three following questions: (i) Why is the trifluoride anion, as well as other trihalide anions, so stable, while $\mathrm{H}_{3}{ }^{-}, \mathrm{CH}_{5}{ }^{-}$, and other transition states of nucleophilic reactions are not? (ii) Why is $\mathrm{F}_{3}{ }^{-}$so prone to undergo symmetry-breaking artifact, and why does it, more generally, pose such a difficult challenge to quantum chemistry? (iii) Why does it dissociate, at high collision energies, to the least stable product?

\section{Theoretical Methods}

The BOVB Method. The BOVB method is an ab initio computational method of valence bond type that has been devised to combine the properties of interpretability and extreme compactness of the wave function with reasonable accuracy of the calculated energies. ${ }^{30}$ The wave function is composed of a set of VB structures that forms a complete and minimal set (also called Rumer basis) for the description of a given electronic state. For the $\mathrm{X}_{3}{ }^{-}$systems, the Rumer basis is composed of six VB structures (see Figure 1). Among the electrons and orbitals, one distinguishes an active space, made of the orbitals and the electrons that are directly involved in the bond breaking/forming, from an inactive space where the orbitals keep the same occupancy throughout the dissociation coordinate. In the $\mathrm{F}_{3}{ }^{-}$trimer, for example, the inactive space is composed of the nine lone pairs, while the active space involves four electrons and three orbitals: a pure atomic p orbital on the central atom, and one hybrid $\sigma$ orbital on each of the remaining atoms. In $\mathrm{H}_{3}{ }^{-}$, all of the electrons and orbitals belong to the active space. Therefore, both $\mathrm{F}_{3}{ }^{-}$and $\mathrm{H}_{3}{ }^{-}$possess a three-electron four-orbital active space. The Rumer basis of VB structures for such an electronic system is made of all of the possible arrangements of four electrons into three orbitals, that can form a singlet state. These VB structures are illustrated in Figure 1 for the active space of $\mathrm{F}_{3}{ }^{-}$, and some comments about the classifications of these structures will be given in the next section. The active space is treated at the VB level and its electrons are explicitly correlated, while the inactive part of the molecule is described as a set of doubly occupied orbitals, so that the correlation of inactive electrons and the active-inactive correlation are not explicitly taken into account. An important feature of our VB calculations is that all of the active orbitals are strictly localized on a single fragment X, like in the classical VB method, so as to ensure a clear correspondence between the mathematical expressions of the VB structures and their physical meaning,

(30) (a) Hiberty, P. C.; Humbel, S.; Byrman, C. P.; van Lenthe, J. H. J. Chem Phys. 1994, 101, 5969. (b) Hiberty, P. C.; Humbel, S.; Archirel, P. J. Phys. Chem. 1994, 98, 11697. (c) Hiberty, P. C. In Modern Electronic Structure Theory and Applications in Organic Chemistry; Davidson, E. R., Ed.; World Scientific: River Edge, NJ, 1997; pp 289-367. (d) Hiberty, P. C.; Shaik, S. In Valence Bond Theory; Cooper, D. L., Ed.; Elsevier: Amsterdam, 2002; pp 187-226. (e) Hiberty, P. C.; Shaik, S. Theor. Chem. Acc. 2002, $108,255$.
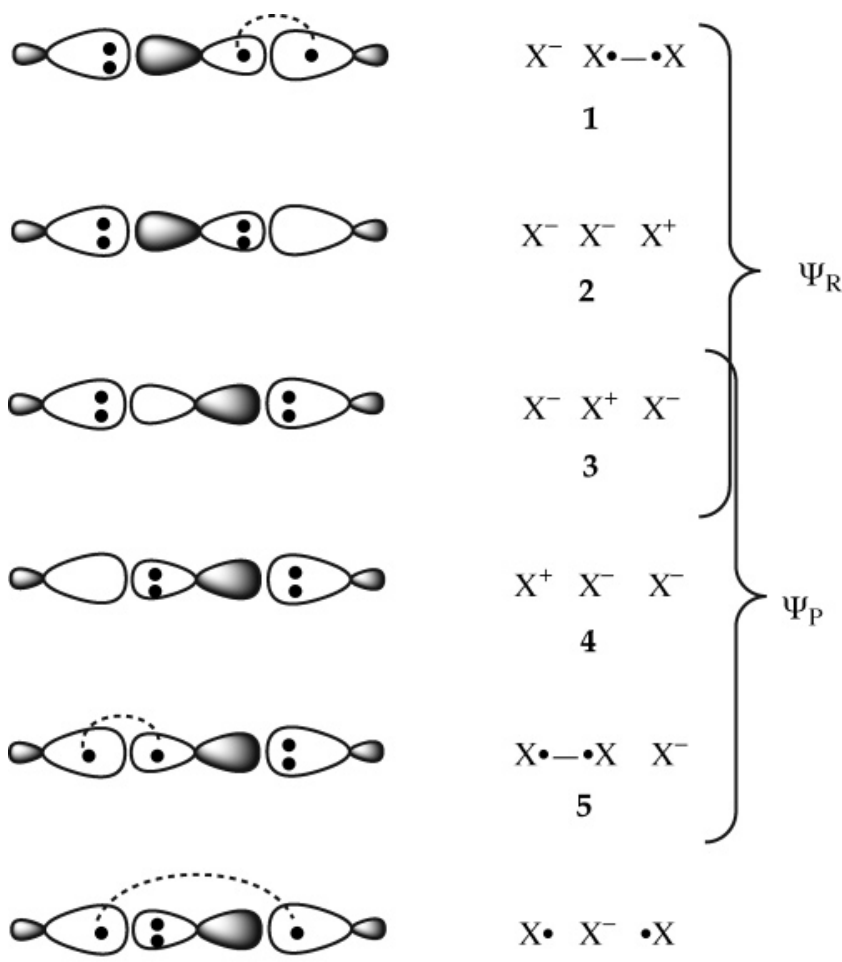

$\mathrm{X} \cdot \mathrm{X}^{-} \cdot \mathrm{X}$

6

Figure 1. Complete basis of VB structures for a four-electron, three-orbital electronic system, illustrated on the $\mathrm{F}_{3}{ }^{-}$example. Only the active electrons and orbitals are represented.

ionic or covalent. This is a fundamental difference between BOVB and the GVB method, the latter dealing with covalent structures only and allowing the orbitals that form a bonding pair to be delocalized on several centers. The coefficients and orbitals of the VB structures are optimized simultaneously, so as to minimize the total energy of the multistructure wave function. During the optimization process, each VB structure is allowed to possess its specific set of orbitals, different from one VB structure to the other. In this manner, the orbitals can fluctuate in size and shape so as to fit the instantaneous charges of the atoms on which these orbitals are located. This specificity of the BOVB method ensures its accuracy by bringing some dynamic correlation to the wave function, without increasing the number of VB configurations.

The BOVB method has a few levels that differ in hierarchy of sophistication. Here, we use the most sophisticated level, referred to as SD-BOVB. This level is characterized by two improvements relative to the basic level: (i) the active doubly occupied orbitals of an ionic structure are split into two singlet-coupled singly occupied orbitals, so as to bring some radial correlation to the active electrons; (ii) the lone pairs are allowed to be delocalized on the three fragments. This does not change the physical meaning of the VB structures, but allows some flexibility in the interactions between lone pairs. Last, in the $\mathrm{H}_{3}{ }^{-}$case, further VB structures displaying $\pi$ occupied orbitals for $\mathrm{H}^{-}$or $\mathrm{H}_{2}$ are added to bring some angular correlation. Previous experience has shown us that such VB structures are not entirely negligible in diatomic molecules such as $\mathrm{H}_{2}, \mathrm{Li}_{2}$, etc. Such structures have small coefficients and will not be considered in the analysis of the wave functions, but are important for improving the accuracy of the calculated energies. Note that analogous structures do not exist in $\mathrm{F}_{3}{ }^{-}$, because the $\pi$ orbital system of this species is saturated.

Basis Sets and Geometries. The capability of BOVB to provide reasonable geometries has been proven in a number of test cases in the past. ${ }^{30}$ However, it has become a standard, in BOVB applications, to optimize and characterize the geometries by means of MO-based computational methods, for the sake of saving computer time. The electronic states are then recalculated and analyzed at the BOVB level. 
In accord, all geometries were optimized at the UMP2 level of calculation (second-order Møller-Plesset perturbation theory in its spinunrestricted formalism) by using a gradient technique and the standard $6-31++\mathrm{G}(\mathrm{d}, \mathrm{p})$ basis set. Calculations of vibrational frequencies, carried out at the same computational level, showed that for all molecules true minima were obtained, except the $\mathrm{H}_{3}{ }^{-}$trimer, which is found to be a transition state as expected.

The BOVB calculations for $\mathrm{F}_{3}{ }^{-}$have been done using the same 6-31++G(d,p) basis set, whereas for $\mathrm{H}_{3}{ }^{-}$the correlation-consistent aug-cc-pvdz basis set was taken, because this basis set involves diffuse $\mathrm{p}$ functions for hydrogen, an essential condition for accurate energetics to be obtained when the molecular system contains some negatively charged hydrogen atoms.

Population Analysis. To better compare the relative importance of the various $\mathrm{VB}$ structures in $\mathrm{H}_{3}{ }^{-}$and $\mathrm{F}_{3}{ }^{-}$, the normalized squares of the coefficients are considered and referred to as "weights" in what follows, rather than the coefficients themselves. For $\mathrm{F}_{3}{ }^{-}$, the population analysis and the calculation of energies are performed in the same basis set. For $\mathrm{H}_{3}{ }^{-}$, the presence of diffuse $\mathrm{s}$ and $\mathrm{p}$ functions on atoms that are very close together poses some problems, as the local character of such basis functions becomes absurd. Therefore, the cc-pvdz basis set, which is devoid of diffuse functions, is used to perform the population analysis of $\mathrm{H}_{3}{ }^{-}$.

Software. The Gaussian 98 series of programs ${ }^{31}$ has been used for all calculations of Møller-Plesset and density functional types. The ab initio valence bond calculations were performed with the XMVB program. ${ }^{32}$

\section{Predictions of Qualitative Valence Bond Theory}

The VB Description of $\mathbf{F}_{3}{ }^{-}$and $\mathbf{H}_{3}{ }^{-}$. The six VB structures that form a complete set for $\mathrm{X}_{3}{ }^{-}(\mathrm{X}=\mathrm{H}, \mathrm{F})$ are shown in Figure 1.

Here, the orbitals are either the 1s atomic orbitals of hydrogen atoms, or the axial $\mathrm{p}$ atomic orbitals of fluorine, the lone pair orbitals being left aside. In what follows, the trimer $\mathrm{X}_{3}{ }^{-}$will be considered as an intermediate, or transition state, in the identical exchange reaction 3 :

$$
\mathrm{X}^{-}+\mathrm{X}-\mathrm{X} \rightarrow[\mathrm{X}-\mathrm{X}-\mathrm{X}]^{-} \rightarrow \mathrm{X}-\mathrm{X}+\mathrm{X}^{-}
$$

In Figure 1, 1 and $\mathbf{5}$ represent fully covalent (also called Heitler-London) structures, in which the electrons that make the bond are singlet-coupled, while $\mathbf{2}, \mathbf{3}$, and $\mathbf{4}$ are ionic structures. Actually, even a homopolar bond that links together two identical fragments is never fully covalent, but incorporates some minor ionic terms. Thus, the so-called "Lewis structure" $\Psi_{\mathrm{R}}$ that represents the reactants in reaction 3 is a variationally optimized mixture of $\mathbf{1}, \mathbf{2}$, and $\mathbf{3}$ as in eq 4 , while the products' Lewis structure $\Psi_{\mathrm{P}}$ is an analogous combination of $\mathbf{5 , 4}$, and $\mathbf{3}$.

$$
\begin{aligned}
& \Psi_{\mathrm{R}}=C_{1}(\mathbf{1})+C_{2}(\mathbf{2})+C_{3}(\mathbf{3}) ; \quad C_{2}=C_{3}<C_{1} \\
& \Psi_{\mathrm{P}}=C_{5}(\mathbf{5})+C_{4}(\mathbf{4})+C_{3}(\mathbf{3}) ; \quad C_{4}=C_{3}<C_{5}
\end{aligned}
$$

(31) Frisch, M. J.; Trucks, G. W.; Schlegel, H. B.; Scuseria, G. E.; Robb, M. A.; Cheeseman, J. R.; Zakrzewski, V. G.; Montgomery, J. A., Jr.; Stratmann, R. E.; Burant, J. C.; Dapprich, S.; Millam, J. M.; Daniels, A. D.; Kudin, K. N.; Strain, M. C.; Farkas, O.; Tomasi, J.; Barone, V.; Cossi, M.; Cammi, R.; Mennucci, B.; Pomelli, C.; Adamo, C.; Clifford, S.; Ochterski, J.; Petersson, G. A.; Ayala, P. Y.; Cui, Q.; Morokuma, K.; Malick, D. K.; Rabuck, A. D.; Raghavachari, K.; Foresman, J. B.; Cioslowski, J.; Ortiz, J. V.; Stefanov, B. B.; Liu, G.; Liashenko, A.; Piskorz, P.; Komaromi, I.; Gomperts, R.; Martin, R. L.; Fox, D. J.; Keith, T.; Al-Laham, M. A.; Peng, C. Y.; Nanayakkara, A.; Gonzalez, C.; Challacombe, M.; Gill, P. M. W.; Johnson, B.; Chen, W.; Wong, M. W.; Andres, J. L.; Gonzalez, C.; HeadGordon, M.; Replogle, E. S.; Pople, J. A. Gaussian 98, revision A.6; Gaussian, Inc.: Pittsburgh, PA, 1998.

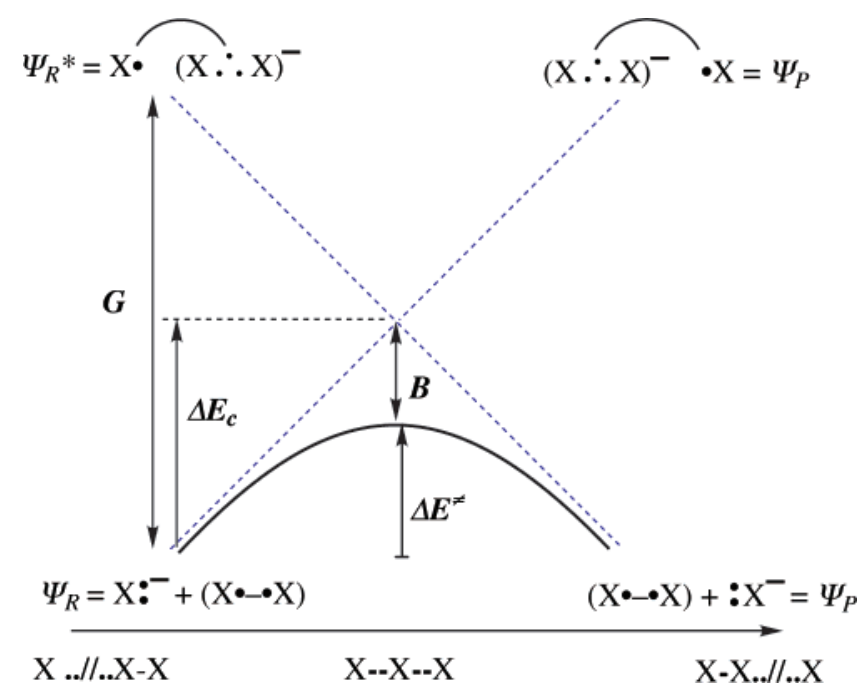

Figure 2. General VBSCD diagram for the identical nucleophilic exchange $\mathrm{X}^{-}+\mathrm{X}_{2} \rightarrow[\mathrm{X}-\mathrm{X}-\mathrm{X}]^{-} \rightarrow \mathrm{X}_{2}+\mathrm{X}^{-}$.

For a description of the reacting system in terms of the products' and reactants' structures, structures 1-5 would form the necessary and sufficient basis set. However, the complete Rumer basis of the $\mathrm{X}_{3}{ }^{-}$cluster includes the additional structure 6, which must therefore be included in the VB calculation. Structure $\mathbf{6}$ is special in that it does not display any bonding interaction, neither covalent nor ionic. As this structure belongs neither to $\Psi_{\mathrm{R}}$ nor to $\Psi_{\mathrm{P}}$ (eq 4 ), it has a zero coefficient in the VB wave function of the reactants or products in reaction 3. On the other hand, structure $\mathbf{6}$ interacts, by virtue of nonzero overlap, with $\mathbf{1 - 5}$ in the geometry of the cluster, and may consequently stabilize the $\mathrm{X}_{3}{ }^{-}$intermediate. As will be seen, and despite its apparently marginal character, structure $\mathbf{6}$ will play a prominent role in differentiating $\mathrm{H}_{3}{ }^{-}$from $\mathrm{X}_{3}{ }^{-}$anions. Whether or not this particular structure needs be included in qualitative studies of nucleophilic reactions or $\mathrm{X}_{3}{ }^{-}$systems, according to the nature of the constituent atoms, will be discussed below.

The main advantage of representing reactions in terms of VB configurations is the unique insight that it brings into reactivity problems. This is the object of the valence bond state correlation diagrams (VBSCD) of Shaik and Pross. ${ }^{33,34}$

The Valence Bond State Correlation Diagrams. The VBSCDs apply to the general category of reactions that can be described as the interplay of two major Lewis structures, that of the reactants and that of the products. One such diagram, as applied to the particular case of the identical nucleophilic reaction 3, is shown in Figure 2. The diagram displays the ground-state energy profile of the reacting system (black curve), as well as the energy profile of each Lewis structure as a function of the reaction coordinate (dotted blue curves). Thus, starting from the reactant's geometry on the left, the Lewis structure that represents the reactant's electronic state, $\Psi_{\mathrm{R}}$, has

(32) Song, L.; Wu, W.; Mo, Y.; Zhang, Q. XMVB-01: An ab initio Nonorthogonal Valence Bond Program; Xiamen University, Xiamen 361005, China, 2003.

(33) (a) Shaik, S. S. J. Am. Chem. Soc. 1981, 103, 3692. (b) Pross, A.; Shaik, S. S. Acc. Chem. Res. 1983, 16, 363. (c) Shaik, S.; Hiberty, P. C. Adv. Quantum Chem. 1995, 26, 100. (d) Shaik, S.; Hiberty, P. C. In Theoretical Models of Chemical Bonding; Maksic, Z. B., Ed.; Springer-Verlag: BerlinHeidelberg, 1991; Vol. 4, pp 269-322. (e) Pross, A. In Theoretical and Physical Principles of Organic Reactivity; John Wiley \& Sons: New York, 1995

(34) Shaik, S.; Shurki, A. Angew. Chem., Int. Ed. 1999, 38, 586. 
the lowest energy and merges with the supersystem's ground state. Then, as one deforms the supersystem toward the products' geometry, the latter Lewis structure gradually rises in energy and finally reaches an excited state $\Psi_{\mathrm{P}} *$ that represents the Lewis structure of the reactants in the products' geometry. Note that in $\Psi_{\mathrm{P}}{ }^{*}$, the isolated $\mathrm{X}$ atom on the right has a single electron, while the two $\mathrm{X}$ atoms that are close together form an $\mathrm{X}_{2}{ }^{-}$anion. A similar diabatic curve can be traced from $\Psi_{\mathrm{P}}$, the Lewis structure of the products in its optimal geometry, to $\Psi_{\mathrm{R}}{ }^{*}$, the same Lewis structure in the reactants' geometry. Consequently, the two curves cross somewhere in the middle of the diagram. The crossing is of course avoided in the adiabatic ground state, because of the resonance energy $B$ that results from the mixing of the two Lewis structures. The barrier is thus interpreted as arising from an avoided crossing between two diabatic curves, which represent the energy profiles of the VB structures of the reactants and products. Qualitatively speaking, it is clear that the higher the crossing point (and thus the larger the quantity $\Delta E_{\mathrm{c}}$ ), the larger the barrier $\Delta E^{\ddagger}$. The height of the crossing point is, on its part, proportional to the energy gap $G$, which is a fundamental parameter of the diagrams. Thus, large $G$ values correspond to high barriers, medium $G$ values correspond to low barriers, and small $G$ values lead to the prediction of negative barriers, that is, stable intermediates.

How does one estimate the parameter $G$ ? This quantity is nothing else but the promotion energy that is required to go from $\Psi_{\mathrm{R}}$ to $\Psi_{\mathrm{R}}{ }^{*}$. For nucleophilic reactions (like $\mathrm{S}_{\mathrm{N}} 2$ reactions or reaction 3 ), $G$ is readily estimated as the ionization potential of the nucleophile, minus the electron affinity of the substrate, eq 5 :

$$
G=\mathrm{IP}\left(\mathrm{X}^{-}\right)-\mathrm{EA}\left(\mathrm{X}_{2}\right)
$$

Ideally, one should use the vertical electron affinity of $X_{2}$ in eq 5. However, for qualitative purposes, what matters is not an exact estimation, but rather an estimation that follows the same tendencies as an exact one in a series of reactions, and if possible related to experimental quantities. Therefore, for the sake of dealing with easily accessible experimental values, the adiabatic electron affinity is usually employed in eq 5 .

In the particular case of an identity exchange reaction such as reaction 3, $G$ may be expressed differently if one considers that the transition from $\Psi_{\mathrm{R}}$ to $\Psi_{\mathrm{R}}$ * can be the outcome of the following thermodynamic cycle:

$$
\begin{aligned}
& \mathrm{X}^{-}+\mathrm{X}_{2} \rightarrow \mathrm{X}^{-}+\mathrm{X}^{\bullet}+\mathrm{X}^{\bullet} ; \quad \Delta E=D_{\mathrm{e}}\left(\mathrm{X}_{2}\right) \\
& \mathrm{X}^{-}+\mathrm{X}^{\bullet}+\mathrm{X}^{\bullet} \rightarrow[\mathrm{X} \therefore \mathrm{X}]^{-}+\mathrm{X}^{\bullet} ; \quad \Delta E=-D_{\mathrm{e}}\left(\mathrm{X}_{2}{ }^{-}\right)
\end{aligned}
$$

There follows a new expression for $G$, that will be more appropriate for the present study:

$$
G=D_{\mathrm{e}}\left(\mathrm{X}_{2}\right)-D_{\mathrm{e}}\left(\mathrm{X}_{2}^{-}\right)
$$

Previous experience of the VBSCD (e.g., in the series of radicals $\left.\mathrm{X}_{3}\right)^{35}$ has shown us that the stable $\mathrm{X}_{3}{ }^{-}$and $\mathrm{X}_{3}{ }^{\bullet}$ symmetric clusters are expected when the gap $G$ is smaller than $2-3 \mathrm{eV}$. With this order of magnitude in mind, applying eq 8 to the $\mathrm{F}_{3}{ }^{-}$case is illuminating: as the bonding energies of $\mathrm{F}_{2}$

(35) Shaik, S. S.; Hiberty, P. C.; Ohanessian, G.; Lefour, J.-M. J. Phys. Chem. 1988, 92, 5086.
Table 1. Weights of the VB Structures for the $\left(X^{-}+X_{2}\right)$ and $X_{3}^{-}$ Systems $(X=H, F)$

\begin{tabular}{lcccccc}
\hline & $\mathbf{1}$ & $\mathbf{2}$ & $\mathbf{3}$ & $\mathbf{4}$ & $\mathbf{5}$ & $\mathbf{6}$ \\
\hline $\mathrm{H}^{-}+\mathrm{H}_{2}$ & 0.936 & 0.032 & 0.032 & & & \\
$\mathrm{~F}^{-}+\mathrm{F}_{2}$ & 0.821 & 0.090 & 0.090 & & & \\
$\mathrm{H}_{3}{ }^{-}(\mathrm{VB}-5)^{a}$ & 0.423 & 0.010 & 0.134 & 0.010 & 0.423 & \\
$\mathrm{~F}_{3}{ }^{-}(\mathrm{VB}-5)^{a}$ & 0.444 & 0.009 & 0.094 & 0.009 & 0.444 & \\
$\mathrm{H}_{3}{ }^{-}(\mathrm{VB}-6)^{b}$ & 0.438 & 0.009 & 0.097 & 0.009 & 0.438 & 0.009 \\
$\mathrm{~F}_{3}{ }^{-}(\mathrm{VB}-6)^{b}$ & 0.336 & 0.006 & 0.062 & 0.006 & 0.336 & 0.256 \\
\hline
\end{tabular}

${ }^{a}$ Calculations involving structures $\mathbf{1}-\mathbf{5}$ only. ${ }^{b}$ Calculations involving all structures 1-6.

and $\mathrm{F}_{2}{ }^{-}$are very close to each other $(38.2$ and $30.2 \mathrm{kcal} / \mathrm{mol}$, respectively), the gap $G$ in the VBSCD is extremely small for $\mathrm{X}=\mathrm{F}$, only $8 \mathrm{kcal} / \mathrm{mol}(0.35 \mathrm{eV})$, thus leading to the qualitative prediction of some stability of $\mathrm{F}_{3}^{-}$relative to $\mathrm{F}_{2}+\mathrm{F}^{-}$. Equation 8 explains the stability of the other trihalide anions in a similar way, with $G$ values in the range $0.4-1.1 \mathrm{eV}$ for $\mathrm{Cl}_{3}{ }^{-}, \mathrm{Br}_{3}{ }^{-}$, and $\mathrm{I}_{3}{ }^{-}$. By contrast, the gap $G$ for the $\mathrm{H}_{3}{ }^{-}$anionic system is certainly much larger: $\mathrm{H}_{2}$ has a bonding energy of $109.5 \mathrm{kcal} /$ mol, and $\mathrm{H}_{2}{ }^{-}$is unbound. This might lead one to conclude that $G$ is larger than $D_{\mathrm{e}}\left(\mathrm{H}_{2}\right)$ in this case; however, the estimation may be refined. $\mathrm{H}_{2}{ }^{-}$is actually a transient species, lower in energy than $\mathrm{H}^{\bullet}+\mathrm{H}^{-}$, however unstable because this species is higher in energy, in its equilibrium geometry, than neutral $\mathrm{H}_{2}$. As a consequence, trying to calculate $\mathrm{H}_{2}{ }^{-}$within $\mathrm{MO}$ theory is difficult, because the highest occupied orbital, when optimized, tends to get infinitely diffuse so as to mimic neutral $\mathrm{H}_{2}$ with an infinitely distant extra electron. Now this problem disappears if one uses VB theory (because of the very different natures of the $\mathrm{H}_{2}$ and $\mathrm{H}_{2}{ }^{-} \mathrm{VB}$ wave functions), so that the stabilization of the transient $[\mathrm{H} \therefore \mathrm{H}]^{-}$species relative to $\mathrm{H}^{\bullet}+\mathrm{H}^{-}$can be estimated to $13.5 \mathrm{kcal} / \mathrm{mol}$ at the SD-BOVB level. Therefore, the gap $G$ amounts to $96 \mathrm{kcal} / \mathrm{mol}$ for reaction 3 with $\mathrm{X}=\mathrm{H}$, typically in the region of reactions displaying barriers. We note that the broad lines of the above explanation for the contrasted behavior of $\mathrm{H}_{3}{ }^{-}$versus $\mathrm{X}_{3}{ }^{-}$have been proposed as early as 1984 by Shaik and Bar. ${ }^{36}$ The testing of the validity of the qualitative model by quantitative calculations now remains.

\section{Results of the BOVB Calculations}

Electronic Structures of $\mathrm{H}_{3}{ }^{-}$and $\mathrm{X}_{3}{ }^{-}$in Terms of Structures 1-5. Let us consider, in a first step, the $\mathrm{H}_{3}{ }^{-}$and $\mathrm{F}_{3}{ }^{-}$system as mere combinations of the reactants' and products' Lewis structures, $\Psi_{\mathrm{R}}$ and $\Psi_{\mathrm{P}}$, in reaction 3 . Thus, while $\mathrm{H}^{-}+$ $\mathrm{H}_{2}$ and $\mathrm{F}^{-}+\mathrm{F}_{2}$ are described in terms of structures $\mathbf{1 - 3}$, the wave functions of $\mathrm{H}_{3}{ }^{-}$and $\mathrm{F}_{3}^{-}$are variationally optimized mixtures of structures $\mathbf{1 - 5}$. This level of calculation is referred to as VB-5 in what follows.

The calculated weights for the various VB structures of $\mathrm{H}_{2}$, $\mathrm{F}_{2}, \mathrm{H}_{3}{ }^{-}$, and $\mathrm{F}_{3}{ }^{-}$are displayed in Table 1 . As expected, $\mathrm{H}_{2}$ and $\mathrm{F}_{2}$ are best described as mainly covalent, with minor but nonnegligible contributions of ionic structures $\mathbf{2}$ and $\mathbf{3}$. Although $\mathrm{F}_{2}$ is slightly less covalent than $\mathrm{H}_{2}$, the VB description of both molecules is essentially the same.

Structures 2 and 4 practically vanish in $\mathrm{H}_{3}{ }^{-}$and $\mathrm{F}_{3}{ }^{-}$, because of the four-electron repulsion arising from the proximity of two negative charges in these structures. On the other hand, the weight of the alternated ionic structure $3\left(\mathrm{X}^{-} \mathrm{X}^{+} \mathrm{X}^{-}\right)$is significant but not overwhelming, and remains lower than that

(36) Shaik, S. S.; Bar, R. Nouv. J. Chim. 1984, 8, 411 
Table 2. Calculated VBSCD Parameters for the Identity Nucleophilic Exchange Reaction 3

\begin{tabular}{cccccc}
\hline & $G^{\mathrm{a}, b}$ & $\Delta E_{\mathrm{c}}(\mathrm{VB}-5)^{b}$ & $B(\mathrm{VB}-5)^{b}$ & $\Delta E^{\ddagger}(\mathrm{VB}-5)^{b}$ & $\Delta E^{\ddagger}(\mathrm{VB}-6)^{c}$ \\
\hline $\mathrm{H}_{3}{ }^{-}$ & $88.4(146.6)$ & 59.5 & 41.6 & 17.9 & 11.8 \\
$\mathrm{~F}_{3}{ }^{-}$ & $5.8(74.8)$ & 35.9 & 38.9 & -3.0 & -31.3 \\
\hline
\end{tabular}

${ }^{a}$ Adiabatic values (vertical values). ${ }^{b}$ Calculations involving structures 1-5 only. ${ }^{c}$ Calculations involving all structures $\mathbf{1 - 6}$.

of the covalent structures $\mathbf{1}$ and $\mathbf{5}$. Moreover, structure $\mathbf{3}$ is not more important in $\mathrm{F}_{3}{ }^{-}$than in $\mathrm{H}_{3}{ }^{-}$. The tentative explanation of the stability of $\mathrm{F}_{3}^{-}$by an important ionic structure $\mathrm{F}^{-} \mathrm{F}^{+} \mathrm{F}^{-}$ is thus ruled out. All in all, at the VB-5 level, the trimers $\mathrm{H}_{3}{ }^{-}$ and $\mathrm{F}_{3}{ }^{-}$resemble each other very much in terms of electronic structures.

Calculated VBSCD Parameters. The calculated values of the $G, \Delta E_{\mathrm{c}}, B$, and $\Delta E^{\ddagger}$ VBSCD parameters for the $\mathrm{H}_{3}{ }^{-}$and $\mathrm{F}_{3}{ }^{-}$systems are displayed in Table 2 . The promotion energy $G$ is calculated as the difference between the energy of $R^{*}$ (involving structures 5 and 6) and the energy or $R$ (involving 1-3). The energies of the crossing point $E_{\mathrm{c}}$, as well as the avoided crossing energy $B$, are naturally calculated at the VB-5 level, involving structures $\mathbf{1}-\mathbf{5}$, because the two crossing curves $\Psi_{\mathrm{R}}$ and $\Psi_{\mathrm{P}}$ involve structures $\mathbf{1 - 3}$ and $\mathbf{3}-\mathbf{5}$, respectively. Last, the reaction barrier $\Delta E^{\ddagger}$ is calculated at both the VB-5 and the VB-6 levels for comparison. All calculations are done with the SD-BOVB method.

The calculated adiabatic values for the promotion energies $G$ amount to 88.4 and $5.8 \mathrm{kcal} / \mathrm{mol}$, respectively, for the $\mathrm{H}_{3}{ }^{-}$ and $\mathrm{F}_{3}{ }^{-}$systems, close to the experimental (or mixed experimental-theoretical) estimations of 96 and $8 \mathrm{kcal} / \mathrm{mol}$ mentioned above. The vertical $G$ values are of course much higher, 146.6 and $74.8 \mathrm{kcal} / \mathrm{mol}$, respectively, but display the same tendencies. Whichever set of $G$ values one prefers to deal with, adiabatic or vertical, both sets predict the energy of the crossing point to be higher for $\mathrm{H}_{3}{ }^{-}$than for $\mathrm{F}_{3}{ }^{-}$, in agreement with the calculated $\Delta E_{\mathrm{c}}$ values displayed in Table $2(59.5$ and $35.9 \mathrm{kcal} / \mathrm{mol}$, respectively). The resonance energies $B$, arising from the mixing of the diabatic curves, are comparable for both systems, so that the barrier $\Delta E^{\ddagger}$ for reaction 3 is much larger for $\mathrm{H}_{3}{ }^{-}$than for $\mathrm{F}_{3}{ }^{-}$, the latter being negative, as postulated in qualitative applications of the VBSCD. However, the quantitative $\Delta E^{\ddagger}$ values are far from being correct at the VB-5 level. The calculated barrier for the $\mathrm{H}_{3}{ }^{-}$exchange amounts to $18 \mathrm{kcal} / \mathrm{mol}$, a rather high value as compared to the estimated barrier of ca. $11 \mathrm{kcal} / \mathrm{mol} .{ }^{37,38}$ As for $\mathrm{F}_{3}{ }^{-}$, being calculated to lie only 3 $\mathrm{kcal} / \mathrm{mol}$ below $\mathrm{F}_{2}+\mathrm{F}^{-}$at this level, its stability is severely underestimated relative to experimental data or accurate calculations. It emerges from the VB-5 study that, if the $\mathrm{H}_{3}{ }^{-}$supersystem may be described roughly as the interplay of the reactant's and product's structures, this description is qualitatively inadequate for $\mathrm{X}_{3}{ }^{-}$, which requires the inclusion of the complete set of VB structures, 1-6, in the BOVB calculation. This level is referred to as VB-6 in what follows.

Full BOVB Calculations Involving Structures 1-6. The effect of including structure $\mathbf{6}$ in the calculation can be appreciated first by considering the weight of this structure in the trimers (Table 1, entries 5 and 6). While this structure has a marginal weight, 0.009 in $\mathrm{H}_{3}{ }^{-}$, and can be considered as

(37) Keil, F.; Ahlrichs, R. J. Am. Chem. Soc. 1976, 96, 4787

(38) Stärk, J.; Meyer, W. Chem. Phys. 1993, 176, 83. having only a corrective effect on the trimer's electronic structure, it has a much larger weight in $\mathrm{F}_{3}{ }^{-}, 0.256$, practically as large as the reactants' and products' structures. The nonbonded structure $\mathbf{6}$ is therefore an essential ingredient of the electronic structure of $\mathrm{F}_{3}{ }^{-}$, which stabilizes it by as much as $28 \mathrm{kcal} / \mathrm{mol}$ relative to the VB-5 level. By contrast, structure 6 stabilizes $\mathrm{H}_{3}{ }^{-}$by only $6 \mathrm{kcal} / \mathrm{mol}$.

At the VB-6 level, our final value for the $\mathrm{H}_{3}{ }^{-}$barrier, 11.8 $\mathrm{kcal} / \mathrm{mol}$, compares well with the theoretical estimate of $11 \pm$ $0.5 \mathrm{kcal} / \mathrm{mol}$ arising from accurate calculations. ${ }^{37,38}$ Our value for the $\mathrm{F}_{3}{ }^{-}$dissociation energy, $31.3 \mathrm{kcal} / \mathrm{mol}$, is slightly outside the experimental window, but close to the best calculation to date. ${ }^{28}$ This CAS $(7,8)+$ PT2 calculation yielded a value of 28 $\mathrm{kcal} / \mathrm{mol}$ in the TZP + basis set. Moreover, reducing the size of the basis set from the $\mathrm{TZP}+$ to the $\mathrm{DZP}+$ basis set increases the bond energy by $1 \mathrm{kcal} / \mathrm{mol} .^{27}$ Thus, our calculated value should be compared to a theoretical estimation of $29 \mathrm{kcal} / \mathrm{mol}$ in a basis set comparable to ours. In this context, the BOVB performance is correct in consideration of the difficulty of the $\mathrm{F}_{3}{ }^{-}$system and the extreme compactness of the wave function. $\mathrm{Be}$ it as it may, the $\Delta E^{\ddagger}$ values provided by the VB-6 level show that a simple description of the $\mathrm{H}_{3}{ }^{-}$and $\mathrm{F}_{3}{ }^{-}$systems in terms of six VB structures captures the essence of the electronic structures of these molecules and should allow a deep understanding of their peculiar properties.

The Two Dissociation Channels of $\mathbf{F}_{\mathbf{3}}{ }^{-}$. The dissociation pathways leading to $\mathrm{F}_{2}+\mathrm{F}^{-}$and to $\mathrm{F}_{2}^{-}+\mathrm{F}^{\bullet}$, reactions 1 and 2 , are rather different because the former starts with an antisymmetric stretching of the trimer, while the latter starts with a symmetric stretching, the $\mathrm{F}-\mathrm{F}$ bond in the three-electronbonded species $\mathrm{F}_{2}{ }^{-}$being longer than the $\mathrm{F}-\mathrm{F}$ bond in the trimer. In accord, the two reactions will be represented by two distinct VB diagrams, Figures 3 and 4. For the $\mathrm{H}_{3}{ }^{-}$system, only reaction 1 will be considered (Figure 5) because $\mathrm{H}_{2}^{-}$is unbound.

For the sake of getting better insight, it is interesting to gather the various VB structures into two distinct diabatic states. The first one is defined as a combination of structures $\mathbf{1 - 5}$, variationally optimized at all points of the reaction coordinate. As this state represents a combination of two-electron-bonded Lewis structures, $\Psi_{\mathrm{R}}$ and $\Psi_{\mathrm{P}}$ (eq 9), it will be referred to as $\Psi(2-e)$.

$$
\Psi(2-\mathrm{e})=\mathrm{X}-\mathrm{X} \mathrm{X}^{-} \leftrightarrow \mathrm{X}^{-} \mathrm{X}-\mathrm{X}
$$

The other diabatic state, $\Psi(3-\mathrm{e})$, will be the optimized combination of structures $\mathbf{1}, \mathbf{5}$, and $\mathbf{6}$. As such, and despite the fact that it shares some common structures with $\Psi(2-\mathrm{e})$ (1 and 5), it may be considered as the resonating combination of two three-electron-bonded combinations, $(\mathbf{1} \leftrightarrow \mathbf{6})$ and $(\mathbf{5} \leftrightarrow \mathbf{6})$, as expressed in eq 10:

$$
\Psi(3-\mathrm{e})=\mathrm{X}^{\bullet}[\mathrm{X} \therefore \mathrm{X}]^{-} \leftrightarrow[\mathrm{X} \therefore \mathrm{X}]^{-} \mathrm{X}^{\bullet}
$$

Let us first consider the dissociation of $\mathrm{F}_{3}{ }^{-}$by reaction 1 , Figure 3. On the left-hand and right-hand sides of the diagram, the geometry of the supersystem corresponds to the equilibrium geometry of $\mathrm{F}_{2}$, with an $\mathrm{F}^{-}$anion being far apart. In this geometry, the $\mathrm{F}_{2}$ bond length, $1.434 \AA$, is much shorter than the optimal bond length for an F $\therefore \mathrm{F}$ three-electron bond, so that $\Psi(3-e)$ is much higher in energy than $\Psi(2-e)$. On the other 


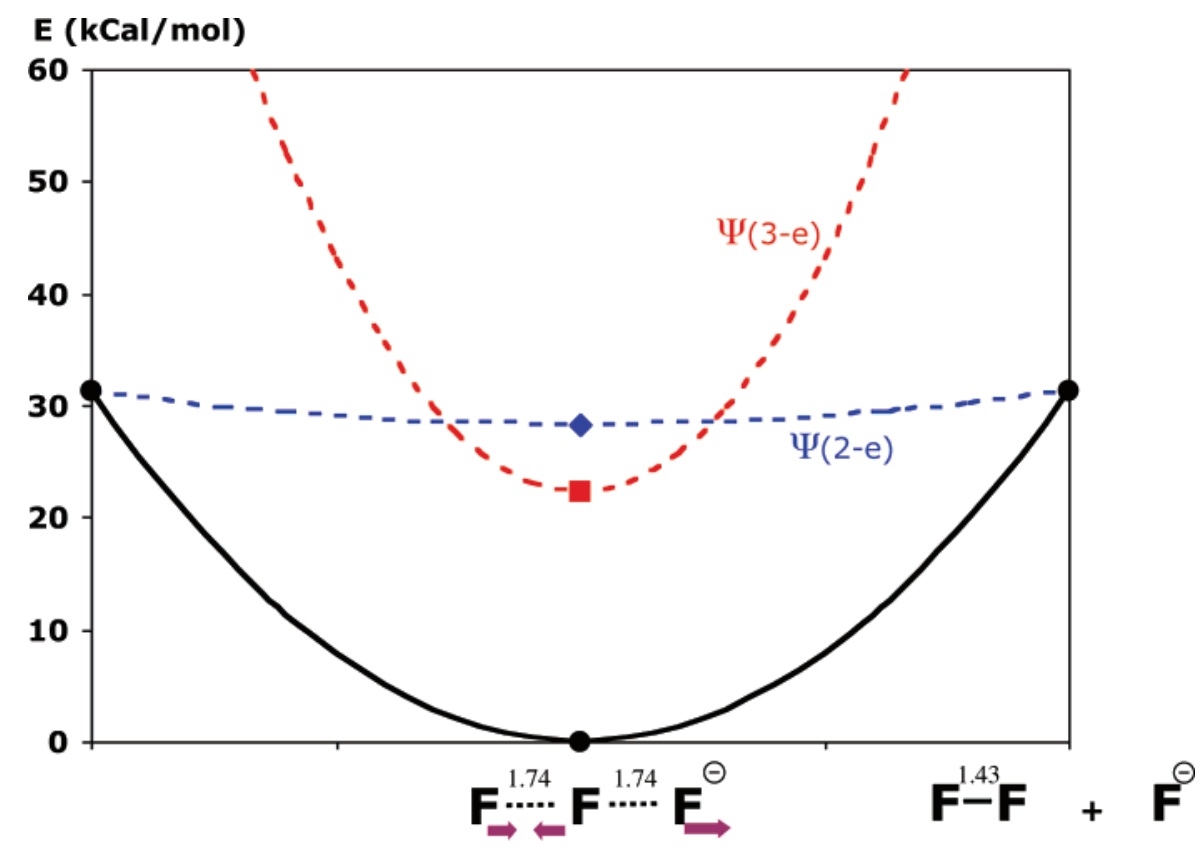

Figure 3. VB diagram for the reaction $\mathrm{F}_{3}^{-} \rightarrow \mathrm{F}_{2}+\mathrm{F}^{-}$, channel (1). Black full curve: ground state. Red and blue dotted curves: $\Psi(3-\mathrm{e})$ and $\Psi(2-\mathrm{e})$ diabatic states.

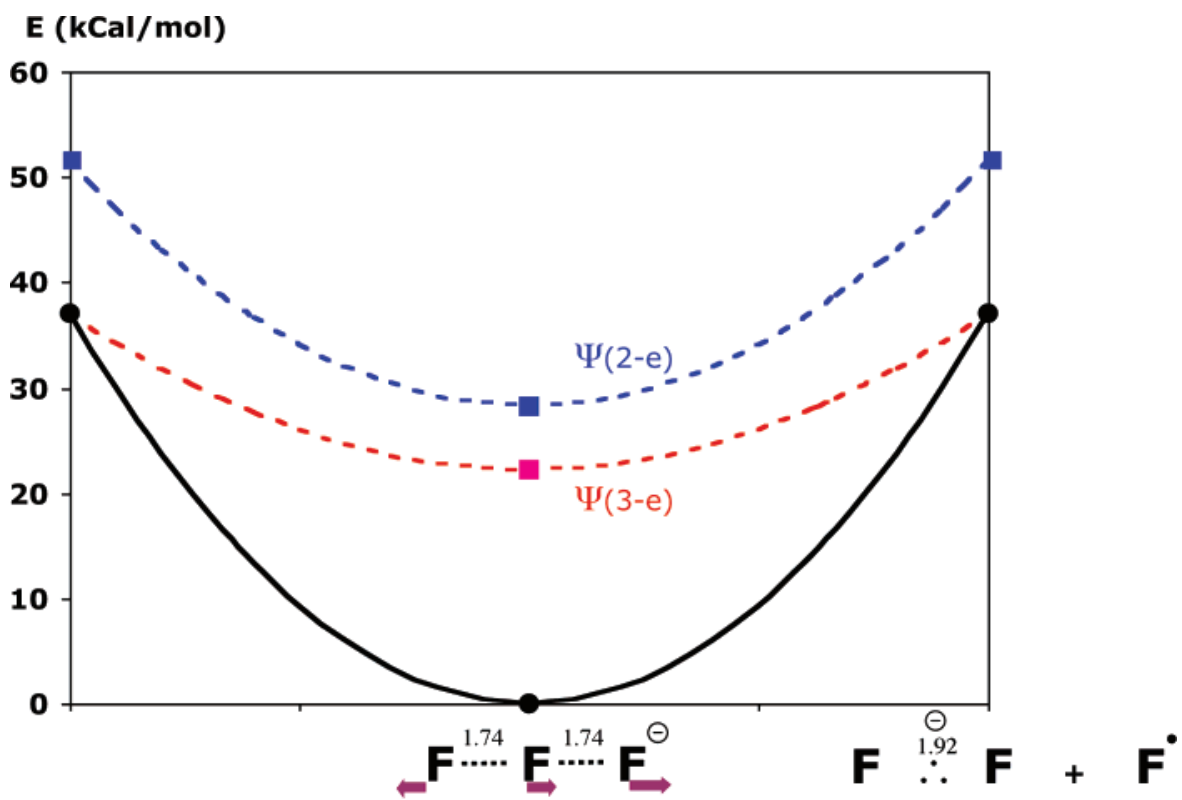

Figure 4. VB diagram for the reaction $\mathrm{F}_{3}{ }^{-} \rightarrow \mathrm{F}_{2}{ }^{-}+\mathrm{F}^{*}$, channel (2). Black full curve: ground state. Red and blue dotted curves: $\Psi(3-\mathrm{e})$ and $\Psi(2-\mathrm{e})$ diabatic states.

hand, the situation is reversed in the middle of the diagram. For this geometry, which is the optimal geometry of the $\mathrm{F}_{3}{ }^{-}$ trimer, with an $\mathrm{F}-\mathrm{F}$ bond of $1.739 \AA$, the diabatic state $\Psi(3-\mathrm{e})$ is so much stabilized that it lies below $\Psi(2-e)$, which means that $\Psi(3-\mathrm{e})$ is closer than $\Psi(2-\mathrm{e})$ to the true nature of the $\mathrm{F}_{3}{ }^{-}$ ground state. In other words, the type of bonding that links together the three atoms in $\mathrm{F}_{3}{ }^{-}$is closer to a three-electron bond than to the classical two-electron $\mathrm{F}-\mathrm{F}$ bond.

The dissociation of $\mathrm{F}_{3}{ }^{-}$through channel (2) displays quite a different type of diagram (Figure 4). Of course, the ordering of the diabatic states is the same as that for reaction 1 (Figure 3) in the middle of the diagram, $\Psi(3-\mathrm{e})$ lying below $\Psi(2-\mathrm{e})$. On the other hand, the ordering of states is reversed relative to reaction 1 on the reactant and product sides of the diagram (left and right extremities). This is because the reaction coordinate, at these points, now displays a long $\mathrm{F}-\mathrm{F}$ bond (1.916 $\AA$ ), corresponding to the optimum bond length of $[\mathrm{F} \therefore \mathrm{F}]^{-}$, and this geometry destabilizes so much the two-electron $\mathrm{F}-\mathrm{F}$ bond that the $\left(\mathrm{F}_{2}+\mathrm{F}^{-}\right)$state lies higher than $\left(\mathrm{F}_{2}^{-}+\mathrm{F}^{\bullet}\right)$. As a consequence, $\Psi(3-\mathrm{e})$ remains lower than $\Psi(2-\mathrm{e})$ at all points of the diagram, meaning that $\mathrm{F}_{3}{ }^{-}$dissociates smoothly by this channel without drastically changing the nature of its electronic structure.

Still another type of diagram is encountered with the dissociation of $\mathrm{H}_{3}{ }^{-}$through channel (1) (Figure 5). This time, it is the two-electron-bonded diabatic state $\Psi(2-e)$ that remains the lowest one at any point of the diagram. The $\Psi(3-\mathrm{e})$ diabatic state, albeit being close to $\Psi(2-\mathrm{e})$ in the middle of the reaction 


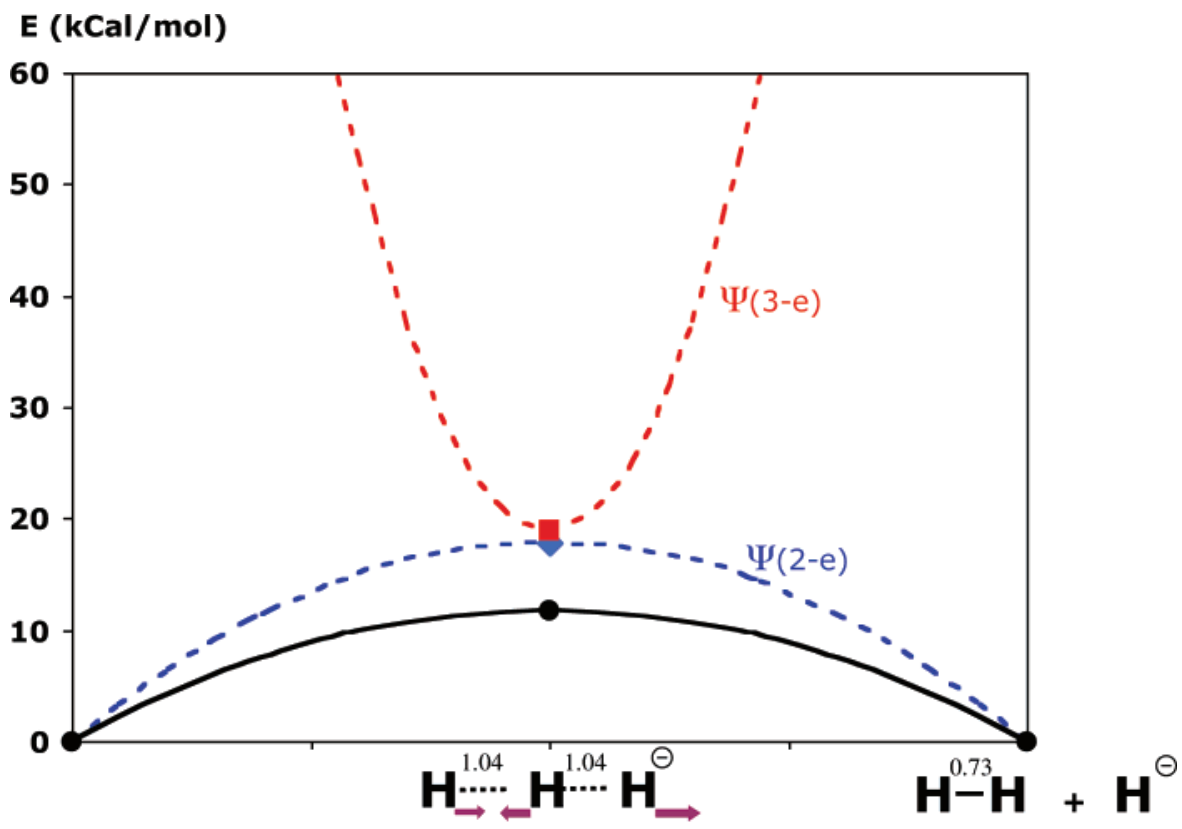

Figure 5. VB diagram for the reaction $\mathrm{H}_{3}{ }^{-} \rightarrow \mathrm{H}_{2}+\mathrm{H}^{-}$. Black full curve: ground state. Red and blue dotted curves: $\Psi(3-\mathrm{e})$ and $\Psi(2-\mathrm{e})$ diabatic states.

coordinate, mixes with it only marginally as can be judged by the rather small stabilization $(6 \mathrm{kcal} / \mathrm{mol})$ arising from this mixing. Thus, unlike the $\mathrm{F}_{3}{ }^{-}$case, the $\mathrm{VB}$ analysis of the $\mathrm{H}_{3}{ }^{-}$ dissociation gets back to a picture that is close to common wisdom for an identity exchange reaction, with a transition state described as a resonating mixture of the reactants' and products' VB structures.

\section{Interpretation of the Results}

The valence bond reading of the electronic structure of $\mathrm{F}_{3}{ }^{-}$ provides an explanation for the preference of reaction 2 over reaction 1 as the major dissociation channel, which, we recall, does not lead to the most stable product. It is common knowledge that, for endothermic reactions leading directly to the products through a monotonic potential surface (without transition states), the preferred reaction channel is governed by thermochemistry at low collision energies, while at slightly higher energies the branching ratio is ruled by considerations of densities of states. However, at much higher energies (e.g., $25 \mathrm{eV}$ in Tuinman's experiment), ${ }^{3}$ diabatic effects become predominant, favoring the dissociation product that most closely resembles the ground state of the starting molecule, in terms of electronic structure. Now the simple picture that is closest to the $\mathrm{F}_{3}{ }^{-}$ground state, $\Psi(3-\mathrm{e})$, is precisely made of the dissociation product of reaction 2 and its mirror image.

The quantitative VB calculations also provide an explanation for the contrasted natures, stable versus unstable, of the $\mathrm{F}_{3}{ }^{-}$ and $\mathrm{H}_{3}{ }^{-}$stationary points. The predominance of structures $\mathbf{1}-\mathbf{5}$ in the description of $\mathrm{H}_{3}{ }^{-}$demonstrates that the corresponding identity exchange reaction can be described as the interplay of two major Lewis structures, that of the reactants and that of the products. On the other hand, the $\mathrm{F}_{3}{ }^{-}$supersystem departs from this simple picture, in that the two-structure representation must be significantly corrected, in the middle of the diagram, by the strong stabilizing effect of the nonbonded structure 6, which belongs neither to the reactants nor to the products. The stability of $\mathrm{F}_{3}{ }^{-}$, as opposed to the unstability of $\mathrm{H}_{3}{ }^{-}$, must be examined at the light of this peculiarity. It emerges from the quantitative
VB study that $\mathrm{F}_{3}{ }^{-}$is stable for two reasons. The first reason, that reveals itself in the framework of a simple (and incomplete) description of $\mathrm{F}_{3}{ }^{-}$in terms of two Lewis structures, lies in the smallness of the $G$ parameter (eq 8) in the VBSCD. The second reason is related to the large and very stabilizing contribution of structure 6 (or three-electron-bonded forms) in the ground state of the trimer. Now why is three-electron bonding competitive in the $\mathrm{F}_{3}{ }^{-}$system, and not in $\mathrm{H}_{3}{ }^{-}$? We believe that the answer lies in the peculiar nature of the two-electron bond in $F_{2}$. As has been shown elsewhere, ${ }^{39} F_{2}$ is the site of a very important lone-pair bond weakening effect (LPBWE), due to a repulsive interaction between lone pairs and between the lone pairs and the electrons of the $\sigma$ bond. As a consequence of these repulsions, $\mathrm{F}-\mathrm{F}$ is in fact a "stretched" bond relative to the optimal bond length for covalent coupling. To better appreciate this stretching, we correlated the bond lengths to the atomic radii in the series $\mathrm{H}_{n} \mathrm{X}-\mathrm{XH}_{n}$ of two-electron bonds $(\mathrm{X}=$ $\mathrm{Li}-\mathrm{F}, n=0-4) .{ }^{39 \mathrm{c}}$ The correlation is strictly linear from Li to $\mathrm{N}$, but deviates from linearity for the $\mathrm{HO}-\mathrm{OH}$ and $\mathrm{F}-\mathrm{F}$ bonds. For this latter bond, extrapolating the straight line would yield a bond length of ca. $1.22 \AA$, to be compared with the real value of $1.412 \AA$. This important stretching has two consequences: (i) the F-F two-electron bond is weak, and this weakness is responsible for the low value of the $G$ parameter of the VBSCD, according to eq 8; (ii) the LPBWE and the corresponding stretching effect are also at work in the trimer, to the extent that the $\mathrm{F}-\mathrm{F}$ interatomic distance, in $\mathrm{F}_{3}{ }^{-}$, approaches the bond length at which the three-electron bond is optimal. This explains why the diabatic $\Psi(3-\mathrm{e})$ state gets lower than $\Psi(2-\mathrm{e})$ and plays such an important role in the $\mathrm{F}_{3}{ }^{-}$trimer, while three-electronbonded forms remain very minor in $\mathrm{H}_{3}{ }^{-}$. All in all, the stability of $\mathrm{F}_{3}{ }^{-}$is therefore related to the LPBWE, an explanation that carries over to the other trihalide anions $\mathrm{X}_{3}{ }^{-}(\mathrm{X}=\mathrm{Cl}-\mathrm{I})$, as well as isoelectronic 22-valence-electron anions $\left(\mathrm{Se}_{3}{ }^{4-}, \mathrm{As}_{3}{ }^{7-}\right.$,

(39) (a) Sini, G.; Maître, P.; Hiberty, P. C.; Shaik, S. S. J. Mol. Struct (THEOCHEM) 1991, 229, 163. (b) Shaik, S. S.; Maître, P.; Sini, G.; Hiberty, P. C. J. Am. Chem. Soc. 1992, 114, 7861. (c) Lauvergnat, D.; Hiberty, P. C. J. Mol. Struct. (THEOCHEM) 1995, 338, 283. 
etc.). ${ }^{18}$ Thus, it is the presence of lone pairs on the $\mathrm{X}$ atoms that explains the stability of the $\mathrm{X}_{3}{ }^{-}$trimers against dissociation to $\mathrm{X}_{2}+\mathrm{X}^{-}$, while $\mathrm{H}_{3}{ }^{-}, \mathrm{CH}_{5}{ }^{-}$, or other weakly polar $\mathrm{S}_{\mathrm{N}} 2$ transition states are unstable.

Let us now turn to the computational difficulties that are associated with the trifluoride anion. As has been seen, $\mathrm{F}_{3}{ }^{-}$has a strong three-electron-bond character, as demonstrated by the major contribution of $\Psi(3-\mathrm{e})$ (eq 10) to its ground state. Now three-electron bonding energies have been shown to be strongly underestimated at the Hartree-Fock level, and to be systematically overestimated by current DFT functionals (with the exception of BHLYP, which is unfortunately inaccurate).$^{40}$ In accord, the dissociation energies of $\mathrm{F}_{3}{ }^{-}$toward $\mathrm{F}_{2}+\mathrm{F}^{-}$(reaction 1), are also underestimated at the Hartree-Fock level, and overestimated at the various DFT levels.

One final remark is in order about the strong tendency of $\mathrm{F}_{3}{ }^{-}$to undergo symmetry-breaking even in large-scale MCSCF computations. ${ }^{28}$ This is, we believe, once again related to the major three-electron-bonded nature of the trimer's ground state. Indeed, it is known that three-electron bonds are subject to symmetry-breaking beyond a specific critical distance. ${ }^{41,42}$ For $\mathrm{F}_{2}{ }^{-}$, this artifact takes place even at equilibrium distance. Of course, it is easy to impose the symmetry of the wave function if $\mathrm{F}_{2}{ }^{-}$is calculated alone, but this is impossible if the $\mathrm{F}_{2}{ }^{-}$entity is flanked by a neighboring $\mathrm{F}$ atom as is the case in the $\mathrm{F}_{3}{ }^{-}$ trimer. Therefore, each $\left(\mathrm{F}^{\bullet}+\mathrm{F} \therefore \mathrm{F}^{-}\right)$entity that composes $\Psi(3-\mathrm{e})$ in eq 10 undergoes a local symmetry-breaking that is difficult to solve, unless costly techniques such as orbital doubling are employed. ${ }^{28}$ This problem does not occur within the BOVB framework, which is, by nature, free from the symmetry-breaking artifact. ${ }^{43}$

\section{Conclusion}

The $\mathrm{H}_{3}{ }^{-}$and $\mathrm{F}_{3}{ }^{-}$hypercoordinated anions have been studied in the ab initio valence bond framework, by means of the BOVB method. In view of the difficulties that are usually encountered in the theoretical description of $\mathrm{F}_{3}{ }^{-}$, this molecule is an

(40) Braïda, B.; Hiberty, P. C. J. Phys. Chem. A 1998, 102, 7872.

(41) Braïda, B.; Lauvergnat, D.; Hiberty, P. C. J. Chem. Phys. 2001, 115, 90

(42) Braïda, B.; Hiberty, P. C. J. Phys. Chem. A 2000, 104, 4618. interesting test case for the BOVB method, which yields reasonable dissociation energies for the two dissociation channels that are considered, despite the extreme compactness of the wave function that involves only six VB configurations.

While $\mathrm{H}_{3}{ }^{-}$belongs to the category of systems that may be described as the interplay of two major VB structures, that of the reactants and that of the products, $\mathrm{F}_{3}{ }^{-}$does not. For this system, an additional nonbonded structure, that plays a role only in the trimer, is of fundamental importance and endows the ground state of $\mathrm{F}_{3}{ }^{-}$with a predominant three-electron bond character. This specificity explains the failure of the HartreeFock and DFT methods to describe this anion, as well as its strong tendency to undergo artifactual symmetry-breaking.

Another consequence of the three-electron bond character of $\mathrm{F}_{3}{ }^{-}$is that the electronic stucture of this anion is closer to the least stable dissociation products, $\mathrm{F}_{2}{ }^{-}+\mathrm{F}^{\bullet}$, than to the most stable products, $\mathrm{F}_{2}+\mathrm{F}^{-}$. This is the reason why, at high collision energies $(25 \mathrm{eV}), \mathrm{F}_{3}{ }^{-}$is found to dissociate predominantly to the least stable products.

The reason for the stability of $\mathrm{F}_{3}{ }^{-}$, as compared to the instability of $\mathrm{H}_{3}{ }^{-}, \mathrm{CH}_{5}{ }^{-}$, or other $\mathrm{S}_{\mathrm{N}} 2$ transition states, is twofold. On one hand, the fact that the three-electron bond in $\mathrm{F}_{2}{ }^{-}$ is almost as strong as the two-electron bond in $\mathrm{F}_{2}$ results in a very low parameter $G$ in a valence bond state correlation diagram of the dissociation reaction, resulting in a negative barrier as predicted by this model. On the other hand, the nonbonded structure that is responsible for the three-electron bond character of the trimer has a very important stabilizing effect in $\mathrm{F}_{3}{ }^{-}$, to be compared with a very weak one in $\mathrm{H}_{3}{ }^{-}$. The two reasons are related to the stretched character of the $\mathrm{F}_{2}$ bond, itself related to the presence of lone pairs. The stability of the other trihalide anions as well as that of other 22-valenceelectron anions is explained the same way. Thus, it appears that the presence of lone pairs on the $\mathrm{X}$ fragment is a fundamental factor of stability for an $\mathrm{X}_{3}{ }^{-}$hypercoordinated anion.

(43) Humbel, S.; Demachy, I.; Hiberty, P. C. Chem. Phys. Lett. 1995, 247, 126. 